\title{
Socio-demographic determinants of vitamin A supplementation in Bangladesh: evidence from two rounds of Bangladesh demographic and health surveys, 2007 and 2011
}

\author{
Manoj Kumar Raut* \\ Regional Manager, Research and Evaluation, Nutrition International, Asia Regional Office, New Delhi, India \\ Received: 10 January 2018 \\ Revised: 03 February 2018 \\ Accepted: 05 February 2018 \\ *Correspondence: \\ Dr. Manoj Kumar Raut, \\ E-mail: rautmanojkumar@gmail.com \\ Copyright: $($ ) the author(s), publisher and licensee Medip Academy. This is an open-access article distributed under \\ the terms of the Creative Commons Attribution Non-Commercial License, which permits unrestricted non-commercial \\ use, distribution, and reproduction in any medium, provided the original work is properly cited.
}

\begin{abstract}
Background: Vitamin A supplementation reduces night blindness, child morbidity and mortality. In Bangladesh, Vitamin A deficiency among children 6-59 months has remained just about stagnant at 20.5 per cent as per the latest Bangladesh National Micronutrient Status Survey 2011-12 declining by a meagre 1.2 per cent from 21.7 per cent in 1997 (IPHN/HKI, 1997). Alarmingly, there is an absolute decline of 24 percentage points in VAS supplementation from 2007 to 2011 according to the Bangladesh Demographic \& Health Surveys (BDHS). The current status of vitamin A supplementation raises concern because the Ministry of Health and Family Welfare (MoHFW)'s Health, Population and Nutrition Sector Development Program (HPNSDP) 2011-2016 target of 90 per cent needs to be achieved by 2016 .

Methods: This paper tries to explore the socio-demographic causes of receipt of Vitamin A in Bangladesh by analysing the data of the demographic and health surveys for 2007 and 2011 using SAS software. A log binomial regression was conducted to explore the effect of education and exposure to mass media on receipt of vitamin A supplementation.

Results: After adjusting for related socio-economic and demographic factors, parent's education and among mass media channels, television seems to play an important role in predicting receipt of Vitamin A, (Prevalence Ratio [PR]: 1.0973, 95\% Confidence Interval [CI] 1.0499-1.1469) in BDHS 2011. Similarly, also those who watched television were more likely to have received vitamin A (Prevalence Ratio [PR]: 1.0542, 95\% Confidence Interval [CI] 1.03041.0784).

Conclusions: It can be concluded that mass media seems to be working well in making the mothers aware about the vitamin A campaign, especially, the exposure to television. Though mother's education was not associated in the 2007 survey, but it was significantly associated with the receipt of vitamin A in the 2011 survey.
\end{abstract}

Keywords: Communication, Counselling, Education, Mass media, Vitamin A supplementation

\section{INTRODUCTION}

Vitamin A deficiency (VAD) is a major public health problem in many developing countries. Vitamin A deficiency causes xerophthalmia, a range of eye conditions from night blindness to more severe clinical outcomes such as keratomalacia and corneal scars, and permanent blindness. WHO recommends vitamin A supplementation with a dose of $30 \mathrm{mg}$ retinol equivalents in infants aged 6-11 months and $60 \mathrm{mg}$ retinol equivalents at least twice a year in young children aged 12-59 months living in settings where vitamin A 
deficiency is a public health problem. A meta-analysis of 17 trials (11 in Asia, 5 in Africa and 1 in Latin America) for all-cause mortality indicated that vitamin A reduces the overall risk of death by $24 \%$ (risk ratio (RR) 0.76 ; $95 \%$ confidence interval (CI) 0.69-0.83). After considering an unpublished cluster-randomized trial involving one million children in north India (the DEVTA trial), vitamin A supplementation reduced the effect size of all-cause mortality from $24 \%$ to $12 \%$ (RR 0.88; 95\% CI 0.84-0.94). ${ }^{1}$ Vitamin A programming was a prerequisite for achieving one of the Sustainable Development Goals (SDG 3, Target 3.2, Indicator 3.2.1) of reducing under five mortality to at least as low as 25 per 1,000 live births by 2030 .

According to the Bangladesh Micronutrient Status Survey, 2011-12, the national prevalence of sub-clinical vitamin A deficiency in the preschool age children, as measured by estimation of the prevalence of low retinol (serum retinol $<0.7 \mathrm{mmol} / \mathrm{l}$ ), was 20.5 per cent. The prevalence among the slum children was 38.1 per cent. ${ }^{2}$ The Lancet maternal and child nutrition survival series (2013) estimated that 2.3 per cent of the total under five deaths (6-59 months) can be attributable to Vitamin A deficiency. Almost half (46 per cent) of the underweight children in the world live in the South-Asian region; the highest incidence of underweight in the world in a region which is house to just 29 per cent of the developing world under-five population. Vitamin A supplementation (VAS) has been undertaken by many countries to reduce night blindness and mortality due to minor illnesses like diarrhoea and measles. In Bangladesh, Vitamin A deficiency among children 6-59 months has remained just about stagnant at 20.5 per cent according to the latest Bangladesh National Micronutrients Status Survey (BNMS) 2011-12 declining by a meagre 1.2 percentage point from 21.7 per cent in 1997 (IPHN/HKI, 1997).
Alarmingly, according to the Bangladesh Demographic \& Health Surveys, there is an absolute decline of 24 percentage point in vitamin A supplementation from 2007 to 2011. The current status of vitamin A supplementation raises concern because the Ministry of Health and Family Welfare (MOHFW)'s Health, Population and Nutrition Sector Development Program (HPNSDP) 2011-2016 target of 90 per cent needs to be achieved by 2016. So, this study tries to explore the socio-demographic causes of receipt of Vitamin A in Bangladesh in 2007 and 2011. This paper presents an analysis of socio-demographic determinants of VAS in Bangladesh with data from two rounds of Demographic \& Health Surveys of 2007 and 2011. In this paper, the data from the cross-sectional study of children under five years from both the surveys have been used. The age group has been taken as 9-59 months to give adequate exposure of 6 months to a child considering the fact that usually vitamin A campaign rounds are held biannually every six months.

\section{A socio-demographic profile of the country}

The country of Bangladesh with a total land area of 147,570 square kilometres is administratively divided into eight divisions and 64 districts. It ranks $8^{\text {th }}$ in population among the all countries in the world. It is projected to be 164.7 million as on $1^{\text {st }}$ July 2017 (UN projections). The total fertility rate (TFR) is 2.3 lifetime births per woman and the Crude Birth Rate (CBR) is 22.6 births per thousand mid-year population. The religious composition of the country is characterized by about 90 per cent Muslims, 9 per cent Hindus and 1 per cent belonging to other religions.

Table 1: Socio-demographic profile of Bangladesh.

\begin{tabular}{|c|c|}
\hline Indicators & Value \\
\hline 1. Administrative divisions* & 8 divisions and 64 districts $^{13}$ \\
\hline 2. Population (Projected, 2017), in million ${ }^{\#}$ & 164.7 \\
\hline Annual Population Growth Rate (2015-2020) $(\%)^{* * *}$ & 1.04 \\
\hline 4. Crude Birth Rate (CBR), births per 1000 mid-year population & 22.6 \\
\hline Total fertility rate (TFR), lifetime births per woman* & 2.3 \\
\hline Infant mortality rate, number of infant deaths per thousand live births* & 43 \\
\hline $\begin{array}{l}\text { 7. Maternal Mortality Ratio (MMR), number of maternal deaths per 100,000 } \\
\text { live births }\end{array}$ & 176 \\
\hline Life Expectancy at Birth (LEB), (in years) ${ }^{\# \# \#}$ & 69 \\
\hline 9. Contraceptive Prevalence Rate (CPR) $(\%)^{*}$ & 61.2 \\
\hline 10. Human development index rank, 2013, (Medium human development) & $142^{\text {nd }}$ \\
\hline \multicolumn{2}{|c|}{$\begin{array}{l}\text { Health Bulletin 2017. Government of Peoples' Republic of Bangladesh, Ministry of Health and Family Welfare; }{ }^{*} \text { Trends in Maternal } \\
\text { Mortality: } 1990 \text { to } 2015 \text { (Estimates by WHO, UNICEF, UNFPA, World Bank Group and the United Nations Population Division, 2015) } \\
\text { *** Department of Economic and Social Affairs, Population Division (2017). World Population Prospects: The 2017 Revision, Key } \\
\text { Findings and Advance Tables. Working Paper No. ESA/P/WP/248; "\#Human Development Report 2014: Sustaining Human Progress: } \\
\text { Reducing Vulnerabilities and Building Resilience, UNDP; ***United Nations, Department of Economic and Social Affairs, Population } \\
\text { Division (2017). World Population Prospects: The 2017 Revision, Volume I: Comprehensive Tables (ST/ESA/SER.A/399); } \\
\text { \#\#t Statistical Pocket Book of Bangladesh, 2013, Bangladesh Bureau of Statistics, Statistics and Informatics Division (SID), Ministry of } \\
\text { Planning; National Institute of Population Research and Training (NIPORT), Mitra and Associates, and ICF International. 2016. } \\
\text { Bangladesh Demographic and Health Survey 2014. Dhaka, Bangladesh, and Rockville, Maryland, USA: NIPORT, Mitra and } \\
\text { Associates, and ICF International. }\end{array}$} \\
\hline
\end{tabular}




\section{Levels of vitamin A deficiency in Bangladesh}

According to the National Micronutrients Status Survey, the prevalence of vitamin A deficiency were $20.5 \%$, $20.9 \%$ and $5.4 \%$ respectively in preschool age children, school age children and the NPNL women. The 1997 Institute of Public Health \& Nutrition (IPHN) /Hellen Keller International (HKI) survey reported the estimates as $21.7 \%, 19.6 \%$ and $5.0 \%$ respectively in the above population groups. In another study in a rural community, the prevalence in 6 month old infants was found to be
$19.0 \%$ (Eneroth, 2010). ${ }^{3}$ According to the data of the national micronutrients status survey, the median daily consumption of vitamin $\mathrm{A}$ in the preschool age children was 270 REs (Retinol Equivalents), against the RDA (Recommended Daily Allowance) of 300-400 REs. In case of the school age children, it was 318 REs, compared to the RDA of 400-600 REs. In the NPNL women, it was 372 REs against the $700 \mathrm{RE}$, the RDA amount. Therefore, it appeared that in all the population groups studied, the consumption did not meet the requirement. $^{2}$

Table 2: Levels of vitamin A deficiency in Bangladesh: 2011-2012 (\%).

\begin{tabular}{|lllll|}
\hline Sub-clinical vitamin A deficiency & National & Rural & Urban & Slums \\
\hline Preschool age (6-59 months of age) & 20.5 & 19.4 & 21.2 & 38.1 \\
\hline School age (6 to 14 years of age) & 20.9 & 20.2 & 22.1 & 27.1 \\
\hline Non-pregnant non-lactating women (15-49 years of age) & 5.4 & 5.4 & 4.9 & 6.9 \\
\hline
\end{tabular}

Note : Retinol deficiency is defined as Serum retinol level of $<0.7 \mathrm{mmol} / \mathrm{l}$ (WHO/IVACG); Source: Bangladesh National Micronutrient Status Survey, 2011-2012

Table 3: Trends in Vitamin A supplementation in Bangladesh: 1999-2000 to 2014 (\%).

\begin{tabular}{|c|c|c|c|c|c|}
\hline Particulars & 1999-2000 & 2004 & 2007 & 2011 & 2014 \\
\hline $\begin{array}{l}\text { Percentage of children age } 6-59 \text { months receiving } \\
\text { Vitamin A supplementation in the } 6 \text { months preceding the survey }\end{array}$ & - & - & 83.5 & 59.5 & 62.1 \\
\hline $\begin{array}{l}\text { Percentage of children age } 9-59 \text { months receiving } \\
\text { Vitamin A supplementation in the } 6 \text { months preceding the survey }\end{array}$ & 80.4 & 81.8 & 88.3 & 61.6 & 63.2 \\
\hline
\end{tabular}

Sources: Bangladesh Demographic \& Health Surveys, 1999-2000, 2004, 2007, 2011 and 2014.

\section{Vitamin A supplementation programme in Bangladesh}

The national vitamin A programme was initially established by the Bangladesh Programme for the Prevention of Blindness with support from the UNICEF. The Government of Bangladesh distributes vitamin A capsules to children of 6-59 months through National Vitamin A Campaign (NVAC). Every year, two rounds of vitamin A capsule supplementation to children aged 659 months are conducted. According to the health bulletin 2017 of the Directorate General of Health Services, Bangladesh, health workers and volunteers administer vitamin A capsules to around 20 million children at more than 140,000 sites located in health facilities, health centers and schools as well as in mobile sites (bus, boat, and railway stations) throughout the country. ${ }^{13}$

\section{Levels and trends in Vitamin A supplementation in Bangladesh}

Vitamin A supplementation among children 9 to 59 months in the 2007 survey was $88.3 \%$ and $61.2 \%$ in the 2011 survey. It was found to vary with age of the child in both the 2007 and 2011 surveys. Higher the age of the child, higher was the vitamin A receipt. In the BDHS 2007 survey, it varied from 33.4\% among the children 6 to 9 months of age to $91.8 \%$ among those who are between 48 to 59 months of age. In the BDHS 2011, it varied from $23.2 \%$ among 6 to 8 months aged children to
63.2\% among those were aged between 48 and 59 months of age. There is a declining trend in the vitamin $\mathrm{A}$ supplementation in Bangladesh in the recent surveys. There is an absolute decline of 24 percentage points and 27 percentage points in percentage of children age 6-59 months receiving vitamin A supplementation in the six months preceding the survey and percentage of children age 9-59 months receiving vitamin A supplementation in the six months preceding the survey in 2011 over 2007. As regards to the administrative divisions, there were six administrative divisions during the 2007 survey and seven divisions during the 2011 survey. In the 2007 survey, it varied from $85.30 \%$ in Barisal to $90.79 \%$ in the Khulna division, while it varied from $51.46 \%$ in Dhaka to $73.85 \%$ in Barisal division in the 2011 survey.

\section{Literature review}

A literature review was undertaken to understand the determinants of vitamin A supplementation in other studies. In a Lancet paper by Stevens et al (2015), using 134 data sources from 83 countries with measured serum retinol concentration data, the prevalence of vitamin A deficiency as serum retinol concentration lower than 0.7 $\mu \mathrm{mol} / \mathrm{L}$ was estimated. According to its findings, in 1991, $39 \%$ (95\% credible interval [CI] 27-52) of children aged 6-59 months in low-income and middle-income countries were vitamin A deficient. In 2013, the prevalence of deficiency was $29 \%$ (95\% CI: 17-42). Vitamin A deficiency significantly declined in east and southeast 
Asia and Oceania from $42 \%(19-70)$ to $6 \%(1-16$; Posterior Probability [PP]>0.99) and from 21\% (11-33) to $11 \%(4-23 ; \mathrm{PP}=0.89)$ in Latin America and the Caribbean. ${ }^{4}$ Agarwal and Agarwal have shown that rural children and children of educated mothers were more likely to receive vitamin A supplementation than others. Children born in a higher birth order (6+) and those residing in states with low levels of social and economic development were only about half as likely to receive vitamin A supplementation as their counterparts in a cross-sectional study of 20,802 children aged 12-35 months whose mothers participated in the third round of the National Family Health Survey (NFHS-3) conducted during 2005-2006, where the association between the socio-economic and demographic characteristics of the children, the social and economic development status of the State in which they reside and vitamin A supplementation status were examined by means of unadjusted and adjusted logistic regression models. ${ }^{5}$ Kamau et al., 2012 found in a cross-sectional study in Kenya found that main factors affecting utilization of Vitamin A Supplementation services was lack of information and awareness among both health workers and mothers. ${ }^{6}$ Kimani-Murage et al., 2012 analyzed the data of Kenya Demographic and Health Survey 2008-09 and found a positive association between receiving vitamin A supplements and stunting levels. They also found a strong negative relationship between receiving vitamin A supplement and underweight status. They found that vitamin A supplementation may be beneficial to the growth of young children. They have also noted that the analysis was not able to establish a causal relationship, given the cross-sectional nature of the data and have thus recommended longitudinal studies to determine causal relationships. ${ }^{7}$ Semba et al found that maternal education is an important factor relating to receipt of a vitamin A capsule in the BDHS 2004 data. A higher level of formal education achieved by girls may be a key factor in breaking the intergenerational cycle of malnutrition and poverty. Since younger maternal age was also associated with the lower coverage, further efforts are, thus, required by the vitamin A supplementation programmes to reach young, uneducated primigravida mothers. Also, children of households of higher socioeconomic status were more likely to have received a vitamin A capsule. ${ }^{8}$ Thapa et al have analysed the data of Nepal demographic and health survey, 2001 and found that the beneficial effect of vitamin $A$ supplementation on child mortality is larger than that found in most earlier clinical studies. This larger effect may be due mainly to the other health related activities undertaken by the female community health volunteers who distribute vitamin A capsules.

\section{Study objectives}

The objectives of the study are to study the relationship between different socio-demographic characteristics, mass media, and vitamin A supplementation among children 9-59 months of age in data of two rounds of Bangladesh demographic and health surveys 2007 and 2011.

\section{METHODS}

The study uses data from the 2007 and 2011 rounds of Bangladesh Demographic and Health Surveys (BDHS). BDHS 2007 and 2011 are the fifth and sixth DHSs undertaken in Bangladesh. ${ }^{10,11}$ The earlier DHSs were implemented in 1993-94, 1996-97, 1999-2000, and 2004. The main objectives of the BDHS are to provide information to meet the monitoring and evaluation needs of health and family planning programs and provide program managers and policy makers involved in these programs with the information they need to plan and implement future interventions. The 2007 and 2011 BDHS were conducted under the authority of the National Institute of Population Research and Training (NIPORT) of the Ministry of Health and Family Welfare. The survey was implemented by Mitra and Associates, a Bangladeshi research firm located in Dhaka. ICF International of Calverton, Maryland, USA, provided technical assistance to the project as part of its international Demographic and Health Surveys program (MEASURE DHS). Financial support was provided by the U.S. Agency for International Development (USAID). DHS sampling weights were applied before analysing the data. The weighted sample of 4,853 and 7,087 children in the age group of 9-59 months has been used in this paper respectively from 2007 and 2011 BDHS surveys. The data was analysed using SAS software. The $p$ value of 0.05 was considered significant. In addition to the bivariate analysis, multivariate analysis was performed to control for the effects of other correlated factors. Multivariate analysis helps to separate out the independent effect of a factor from the effects of other correlated factors or covariates. As the dependent variable is categorical and dichotomous in nature with two categories; non-receipt of vitamin $\mathrm{A}=0$ and receipt of vitamin $\mathrm{A}=1$, a $\log$ binomial regression was conducted to explore the effect of education and exposure to mass media on receipt of vitamin A supplementation. The logbinomial model is similar to logistic regression in assuming a binomial distribution of the outcome. If the incidence of an outcome of interest in the study population is low (10\%), the odds ratio is close to the risk ratio. However, the more frequent the outcome becomes, the more the odds ratio will overestimate the risk ratio when it is more than 1 or underestimate the risk ratio when it is less than 1 . It is recommended to use $\log$ binomial model, if the indicator of interest if greater than $10 \%$. In this model, SAS computes a prevalence ratio. It is also recommended to be used in cross-sectional studies, in which the prevalence ratio rather than the risk ratio will be generated (Zhang and $\mathrm{Yu}) .{ }^{12}$

\section{RESULTS}

\section{Predictors used in the model}

Background community level and individual level sociodemographic and socio-economic covariates/ predictors, which are expected to influence the receipt of vitamin A have been described here. The predictors used in the 
model are the place of residence, regions (divisions) of the country, age group, education of the mother and father, current work status of the mother and father, and exposure to mass media. The percentage distribution of the covariates or predictors has been described in Table 4. In the 2011 survey, the sample was 77.84 percent rural. A little more than a fourth of the women are non-literate (20.56 per cent), while a little less than a third (30.02 per cent) of their spouses were non-literate. About a half of the caregivers, belong to the age group of 15-24 years, 43.16 per cent belong to 25-34 years and one in ten belong to the age group of 35-49 years. A little more than one out of ten of the respondents were working currently, while more than nine out of ten of their spouses were reported to be working currently. Fifteen per cent of respondents had exposure to newspaper and nine per cent to radio, while more than half were exposed to television.
In the 2007 survey, the sample was 79.02 percent rural. A little more than a fifth of the women are non-literate (27.56 per cent), while a little more than a third (35.36 per cent) of their spouses are non-literate. About a half of the caregivers, belong to the age group of 15-24 years, 41.19 per cent belong to 25-34 years and one in ten belong to the age group of 35-49 years. A little more than one in five of the respondents were working currently, while more than nine out of ten of their spouse reporting to be working currently. Thirteen per cent of respondents had exposure to the newspaper, twenty four per cent to radio, while more than half had were exposed to television. It was observed that 61.92 per cent of the children in the age group of 9 to 59 months had received vitamin $A$ in the last six months preceding the survey in 2011 and 88.59 per cent in 2007.

Table 4: Socio-demographic-economic variables in Bangladesh, BDHS 2007 and BDHS 2011 (\%).

\begin{tabular}{|c|c|c|c|}
\hline Predictors used in the model & Categories & BDHS, 2011 & BDHS, 2007 \\
\hline $\mathbf{N}$ & & 7,087 & 4,853 \\
\hline \multicolumn{4}{|l|}{ Background - community level covariates } \\
\hline \multirow[t]{2}{*}{ Place of residence } & Rural & 77.84 & 79.02 \\
\hline & Urban & 22.16 & 20.98 \\
\hline \multirow[t]{7}{*}{ Division } & Barisal & 5.69 & 6.34 \\
\hline & Chittagong & 22.73 & 21.88 \\
\hline & Dhaka & 31.05 & 31.91 \\
\hline & Khulna & 9.18 & 9.92 \\
\hline & Rajsahi & 12.80 & 21.32 \\
\hline & Rangpur & 10.75 & - \\
\hline & Sylhet & 7.81 & 8.63 \\
\hline \multicolumn{4}{|l|}{ Background - Individual Level covariates } \\
\hline \multirow{2}{*}{ Mother's Education } & Non-literate & 20.56 & 27.56 \\
\hline & Literate & 79.44 & 72.44 \\
\hline \multirow[t]{2}{*}{ Father's Education } & Non-literate & 30.02 & 35.36 \\
\hline & Literate & 69.98 & 64.64 \\
\hline \multicolumn{4}{|l|}{ Demographic covariates } \\
\hline \multirow[t]{3}{*}{ Age of the Mother } & $15-24$ years & 47.54 & 47.86 \\
\hline & 25-34 years & 43.16 & 41.19 \\
\hline & $35-49$ years & 9.30 & 10.94 \\
\hline \multicolumn{4}{|l|}{ Socio-economic covariates } \\
\hline \multirow[t]{2}{*}{ Mother's Work Status } & Not working currently & 90.06 & 71.99 \\
\hline & Working currently & 9.94 & 28.01 \\
\hline \multirow[t]{2}{*}{ Father's Work Status } & Not working currently & 2.45 & 3.13 \\
\hline & Working currently & 97.55 & 96.87 \\
\hline \multicolumn{4}{|l|}{ Communication Exposure } \\
\hline \multicolumn{4}{|l|}{ Mass Media } \\
\hline \multirow[t]{2}{*}{ Newspaper } & Never read Newspaper & 85.01 & 86.55 \\
\hline & Read Newspaper & 14.99 & 13.45 \\
\hline \multirow[t]{2}{*}{ Radio } & Never listened to Radio & 90.58 & 76.23 \\
\hline & Listened to Radio & 9.42 & 23.77 \\
\hline \multirow[t]{2}{*}{ Television } & Never watched TV & 41.51 & 47.64 \\
\hline & Watched TV & 58.49 & 52.36 \\
\hline \multirow[t]{2}{*}{$\begin{array}{l}\text { Vitamin A receipt among 9-59 months of } \\
\text { children (weighted) }\end{array}$} & Non-receipt of Vitamin A & 38.08 & 11.41 \\
\hline & Receipt of Vitamin A & 61.92 & 88.59 \\
\hline
\end{tabular}




\section{Bivariate and multivariate analysis}

Bivariate and multivariate analyses were carried out. The determinants, which were found to be significant, were education of the caregiver and her spouse and exposure to newspaper and television. It was observed that after adjusting for the potential socio-economic and demographic confounders, mother's education and exposure to communication on television were strongly associated with receipt of vitamin A in the BDHS 2011 survey. Those caregivers, who were literate, were 1.313 times more likely to received vitamin A compared to those who were non-literate. Watching television was found to be positively associated with the receipt of vitamin A. Those who reported watching television, were 1.0973 times and 1.0542 times higher likelihood of receiving vitamin A supplementation in the 2011 and 2007 surveys respectively.

Table 5: Receipt of vitamin A in the last six months by socio-demographic-economic variables in Bangladesh, 2007 and 2011.

\begin{tabular}{|c|c|c|c|c|c|c|c|}
\hline \multirow[b]{2}{*}{$\begin{array}{l}\text { Predictors used in } \\
\text { the model }\end{array}$} & \multirow[b]{2}{*}{ Categories } & \multicolumn{3}{|c|}{ BDHS, 2011} & \multicolumn{3}{|c|}{ BDHS, 2007} \\
\hline & & $\begin{array}{l}\text { Vitamin A } \\
\text { Non- } \\
\text { Receivers } \\
(\%)\end{array}$ & $\begin{array}{l}\text { Vitamin } \\
\text { A } \\
\text { Receivers } \\
(\%)\end{array}$ & Prob. & $\begin{array}{l}\text { Vitamin A } \\
\text { Non- } \\
\text { Receivers } \\
(\%)\end{array}$ & $\begin{array}{l}\text { Vitamin } \\
\text { A } \\
\text { Receive } \\
\text { rs }(\%)\end{array}$ & Prob. \\
\hline $\mathbf{N}$ & & 2,699 & 4,388 & & 554 & 4,299 & \\
\hline \multicolumn{8}{|c|}{ Background - community level covariates } \\
\hline \multirow[t]{2}{*}{ Place of residence } & Rural & 37.69 & 62.31 & & 11.94 & 88.06 & \\
\hline & Urban & 39.46 & 60.54 & 0.2021 & 9.42 & 90.58 & 0.0244 \\
\hline \multirow[t]{7}{*}{ Division } & Barisal & 26.15 & 73.85 & & 14.70 & 85.30 & \\
\hline & Chittagong & 30.12 & 69.88 & & 13.73 & 86.27 & \\
\hline & Dhaka & 48.54 & 51.46 & & 10.05 & 89.95 & \\
\hline & Khulna & 42.88 & 57.12 & & 9.21 & 90.79 & \\
\hline & Rajsahi & 30.79 & 69.21 & & 10.78 & 89.22 & \\
\hline & Rangpur & 42.15 & 57.85 & & - & - & \\
\hline & Sylhet & 29.03 & 70.97 & $<0.0001$ & 12.23 & 87.77 & 0.0114 \\
\hline \multicolumn{8}{|c|}{ Background - Individual level covariates } \\
\hline \multirow[t]{2}{*}{ Mother's Education } & Non-literate & 45.27 & 54.73 & & 13.05 & 86.95 & \\
\hline & Literate & 36.22 & 63.78 & $<0.0001$ & 10.79 & 89.21 & 0.0266 \\
\hline \multirow[t]{2}{*}{ Father's Education } & Non-literate & 42.94 & 57.06 & & 12.20 & 87.80 & \\
\hline & Literate & 35.99 & 64.01 & $<0.0001$ & 10.98 & 89.02 & 0.2007 \\
\hline \multicolumn{8}{|c|}{ Demographic covariates } \\
\hline \multirow[t]{3}{*}{ Age of the Mother } & $15-24$ years & 40.73 & 59.27 & & 12.39 & 87.61 & \\
\hline & $25-34$ years & 35.26 & 64.74 & & 9.86 & 90.14 & \\
\hline & $35-49$ years & 37.64 & 62.36 & $<0.0001$ & 12.96 & 87.04 & 0.0166 \\
\hline \multicolumn{8}{|c|}{ Socio-economic covariates } \\
\hline \multirow[t]{2}{*}{$\begin{array}{l}\text { Mother's Work } \\
\text { Status }\end{array}$} & $\begin{array}{l}\text { Not working } \\
\text { currently }\end{array}$ & 37.88 & 62.12 & & 11.61 & 88.39 & \\
\hline & Working currently & 39.90 & 60.10 & 0.2928 & 10.89 & 89.11 & 0.4744 \\
\hline \multirow[t]{2}{*}{ Father's Work Status } & $\begin{array}{l}\text { Not working } \\
\text { currently }\end{array}$ & 32.54 & 67.46 & & 14.66 & 85.34 & \\
\hline & Working currently & 38.22 & 61.78 & 0.1283 & 11.31 & 88.69 & 0.2007 \\
\hline \multicolumn{8}{|c|}{ Communication exposure mass media } \\
\hline \multirow[t]{2}{*}{ Newspaper } & $\begin{array}{l}\text { Never read } \\
\text { Newspaper }\end{array}$ & 39.17 & 60.83 & & 11.93 & 88.07 & \\
\hline & Read Newspaper & 31.90 & 68.10 & $<0.0001$ & 8.06 & 91.94 & 0.0038 \\
\hline \multirow[t]{2}{*}{ Radio } & $\begin{array}{l}\text { Never listened to } \\
\text { Radio }\end{array}$ & 38.61 & 61.39 & & 11.62 & 88.38 & \\
\hline & Listened to Radio & 32.94 & 67.06 & 0.0041 & 10.73 & 89.27 & 0.4036 \\
\hline \multirow[t]{2}{*}{ Television } & Never watched TV & 41.15 & 58.85 & & 13.94 & 86.06 & \\
\hline & Watched TV & 35.90 & 64.10 & $<0.0001$ & 9.11 & 90.89 & $<0.0001$ \\
\hline
\end{tabular}

Prob.: Probability value 
Table 6: Prevalence ratio from the multivariate log binomial regression model of factors associated with receipt of vitamin $A$ in the last six months in Bangladesh, 2007 \& 2011.

\begin{tabular}{|c|c|c|c|c|}
\hline \multirow[b]{2}{*}{ Covariates } & \multicolumn{2}{|l|}{ BDHS, 2011} & \multicolumn{2}{|l|}{ BDHS, 2007} \\
\hline & $\begin{array}{l}\text { Prevalence Ratio }(95 \% \\
\text { CI)*** }\end{array}$ & Prob. & $\begin{array}{l}\text { Prevalence Ratio (95\% } \\
\text { CI)*** }\end{array}$ & Prob. \\
\hline $\mathbf{N}$ & 7,087 & & 4,853 & \\
\hline \multicolumn{5}{|l|}{ Mother's education } \\
\hline Non-literate ${ }^{R e f}$ & 1.000 & & 1.000 & \\
\hline Literate & $1.313(1.0698-1.1964)$ & $<0.0001$ & $1.0069(0.9807-1.0337)$ & 0.6106 \\
\hline \multicolumn{5}{|l|}{ Father's education } \\
\hline Non-literate ${ }^{R e f}$ & 1.000 & & 1.000 & \\
\hline Literate & $1.0709(1.0236-1.1203)$ & 0.0029 & $1.0076(0.9846-1.0311)$ & 0.5224 \\
\hline \multicolumn{5}{|l|}{ Exposure to mass media } \\
\hline Never read Newspaper ${ }^{R e f}$ & 1.0000 & & 1.000 & \\
\hline Read Newspaper & $1.0317(0.9739-1.0931)$ & 0.2888 & $1.0180(0.9915-1.0453)$ & 0.1850 \\
\hline Never listened to Radio $^{\text {Ref }}$ & 1.0000 & & 1.000 & \\
\hline Listened to Radio & $0.9368(0.8820-0.9950)$ & 0.0336 & $0.9961(0.9733-1.0195)$ & 0.7435 \\
\hline Never watched $\mathrm{TV}^{\text {Ref }}$ & 1.0000 & & 1.000 & \\
\hline Watched TV & $1.0973(1.0499-1.1469)$ & $<0.0001$ & $1.0542(1.0304-1.0784)$ & $<0.0001$ \\
\hline
\end{tabular}

CI: Confidence Interval, Ref: Refers to Reference Category. ***Adjusted for place of residence (rural and urban), divisions of the country, working status of both the mother and father. Prob.: Probability value

\section{DISCUSSION}

This is an exploratory study. The study tries to understand the association of different sociodemographic factors with vitamin A supplementation in Bangladesh. The multivariate analysis revealed that among the various channels of mass media, exposure to television is an important factor determining and predicting the receipt of vitamin A among children 9-59 months of age after adjusting for all other relevant factors in both the surveys of 2007 and 2011.

According to the BNMS survey, 2011-12 report, the reason for the decline in VAS from 2007 to 2011 survey could be attributed to the exclusion of the national immunization days by the "six-month margin" prior to the survey (BDHS 2011), which failed to account for considerably in the estimate. The BDHS 2011 survey was conducted during July to December 2011. The latest national immunization day prior to the survey was held on May 29, 2011. In the BNMS survey, the coverage was 77 per cent. The BNMS survey started on October 4, 2011 and continued until December 20, 2011. Therefore the last three weeks time of the survey was outside the "six-month margin" from the last immunization day (May 29, 2011), hence although the survey suffered less than the BDHS 2011, in regard to missing out coverage data, a subtle amount of additional coverage estimate was not accounted into it. Therefore, by and large the coverage of vitamin A supplementation in the preschool age children remains similar to the BDHS 2007 estimate

\section{CONCLUSION}

It can be concluded that mass media seems to be working well in making the mothers aware about the vitamin A campaign, especially, the exposure to television. Though mother's education was not so in the 2007 survey, but it was significantly associated with the receipt of vitamin A in 2011 survey. With increasing viewership of television and the positive relationship between watching television and receipt of vitamin $\mathrm{A}$, it is recommended that the information regarding the campaign should be propagated through different channels in television. In recent future, increased use of mobile phones and social media have expanded the scope of sending message alerts through these channels, which could be effectively tapped and utilized for increased receipt of vitamin A

\section{ACKNOWLEDGEMENTS}

The authors acknowledge the use of the data published on the public domain by DHS program implemented by ICF International and partners Blue Raster, The Futures Institute, The Johns Hopkins Bloomberg School of Public Health Center for Communication Programs (JHUCCP), PATH, and Vysnova, and two new partner organizations in 2013-EnCompass and Kimetrica.
Funding: No funding sources
Conflict of interest: None declared
Ethical approval: Procedures and questionnaires for
standard DHS surveys have been reviewed and approved by ICF Institutional Review Board (IRB). 


\section{REFERENCES}

1. WHO. Vitamin A supplementation in infants and children 6-59 months of age. Geneva, World Health Organization, 2011.

2. ICDDR,B, UNICEF, GAIN, Institute of Public Health and Nutrition, 2013, Bangladesh National Micronutrients Status Survey, 2013.

3. Hanna Eneroth, Shams El Arefeen, Lars AkePersson, Bo Lonnerdal, Bakhtiar Hossain, Charles Stephensen, Eva Charlotte Ekstrom., Maternal Multiple Micronutrient Supplementation Has Limited Impact on Micronutrient Status of Bangladeshi Infants Compared with Standard Iron and Folic Acid Supplementation. J Nutr. 2010:140:618-24.

4. Stevens GA, Bennett JE, Hennocq Q, Lu Y, DeRegil LM, Rogers L, et al. Trends and mortality effects of vitamin A deficiency in children in 138 low-income and middle-income countries between 1991 and 2013: a pooled analysis of populationbased surveys, 2015, Lancet Glob Health, 2015:;3(9):e528-36.

5. Agrawal S, Agrawal PK. Vitamin A supplementation among children in India: Does their socio-economic status and the economic and social development status of their state of residence make a difference? Int J Med Public Health. 2013;3:4854.

6. Kamau MW, Makokha AO, Mutai JK, Mugoya IK. Factors influencing vitamin A supplementation among mothers of children under five years old at Mbagathi district hospital, Kenya. East African Med J. 2012;89(4).

7. Kimani-Murage EW, Ndedda C, Raleigh K, Masibo P. Vitamin A Supplementation and Stunting Levels Among Two Year Olds in Kenya: Evidence from the 2008-09 Kenya Demographic and Health
Survey, International Journal of Child Health and Nutrition 2012;1:135-47.

8. Semba RD, De PS, Sun K, Akhter N, Bloem MW, Raju VK. Coverage of Vitamin A Capsule Programme in Bangladesh and Risk Factors Associated with Non-receipt of Vitamin A, Journal of Health Population \& Nutrition, 2010;28(2):143-8.

9. Thapa S, Choe, Kim M, Retherford, Robert D. Effects of vitamin A supplementation on child mortality: evidence from Nepal's 2001 Demographic and Health Survey, Tropical Medicine and International Health, 2005;10(8):782-9.

10. National Institute of Population Research and Training (NIPORT), Mitra and Associates, and ICF International, Bangladesh Demographic and Health Survey 2011. Dhaka, Bangladesh and Calverton, Maryland, USA: NIPORT, Mitra and Associates, and ICF International, 2013.

11. National Institute of Population Research and Training (NIPORT), Mitra and Associates, and ICF International, Bangladesh Demographic and Health Survey 2014. Dhaka, Bangladesh, and Rockville, Maryland, USA: NIPORT, Mitra and Associates, and ICF International, 2016.

12. Zhang J, Yu KF. What's relative risk?. A method of correcting the odds ratio in cohort studies of common outcomes. JAMA. 1998;280:1690-1.

13. Government of the People's Republic of Bangladesh Ministry of Health and Family Welfare, Health Bulletin 2017, Management Information System, Directorate General of Health Services, Mohakhali, Dhaka, 2017.

Cite this article as: Raut MK. Socio-demographic determinants of vitamin A supplementation in Bangladesh: evidence from two rounds of Bangladesh demographic and health surveys, 2007 and 2011. Int J Community Med Public Health 2018;5:1149-56. 